\title{
Total Migration of the Lumbo-peritoneal valve from D4 to V4: Case Report
}

K.Khalfi ${ }^{{ }^{*}}$, N.Habchi ${ }^{1}$, I.Ikhlef ${ }^{2}$, M.Djaafer ${ }^{1}$

${ }^{1}$ Neurosurgery Department, Mustapha Pacha University Hospital, Algiers, Algeria

${ }^{2}$ Anesthesia resuscitation department, Mustapha Pacha University Hospital, Algiers, Algeria

*Corresponding Author: K.Khalfi, Neurosurgery Department, Mustapha Pacha University Hospital, Algiers, Algeria

Received date: December 14, 2021; Accepted date: December 30, 2021; Published date: January 05, 2022

Citation: K.Khalfi, N.Habchi, I.Ikhlef, M.Djaafer (2022). Total Migration of the Lumbo-peritoneal valve from D4 to V4: Case Report. J. Archives of Medical Case Reports and Case Study, 5(1); DOI:10.31579/2692-9392/0100

Copyright: (C) 2022 K.Khalfi, This is an open access article distributed under the Creative Commons Attribution License, which permits unrestricted use, distribution, and reproduction in any medium, provided the original work is properly cited.

\section{Abstract}

The valve devices are designed for the treatment of hydrocephalus, Ventriculoperitoneal shunt (VPS) and lumbopperitoneal shunt (LPS), but they have two complications: infectious and mechanical. Among the latter, we find the dysconnection and migrations of parts of the valves either in the intracranial ventricular cavities or in the natural cavities of the patient's body (heart, colon, bladder, lung, vena cava, etc.) even externalization. through natural orifices.

Key words: hydrocephalus; lumbopperitoneal bypass; valve dysfunction

\section{INTRODUCTION}

The derivations represent the classic treatment of hydrocephalus and constitute by far the most used mode of treatment [1] this method essentially comprises two types of complications, mechanical and infectious, valve migrations are part of the first group which represents up to $40 \%$ of cases. [1,2]

The LPS proposed in the treatment of chronic hydrocephalus in adults or severe benign HIC present the same complications with the risks of disconnection or migration which necessitate surgical revisions.

\section{OBSERVATION}

Reporting the case of a 33-year-old woman operated on for a benign HIC by placing a lumbopperitoneum bypass (LPB) in 2008, and then she underwent a re-operation for valve dysfunction in 2011.

Recently and for 10 days, the patient gave birth by cesarean section; she consults for the appearance of a HIC syndrome made of intense headaches with a very important bilateral decrease in visual acuity, also she reports the notion of sciatica in the left lower limb

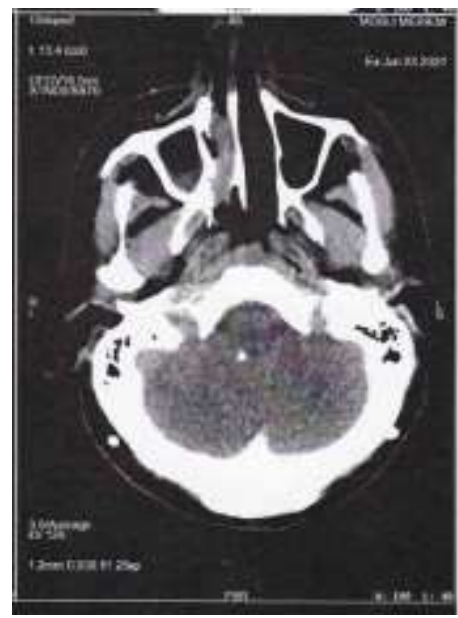


The ophthalmologic examination finds at the OF: a bilateral papillary edema stage II associated with a significant decrease in visual acuity quantified at $1 / 10$ on the right and $4 / 10$ on the left.

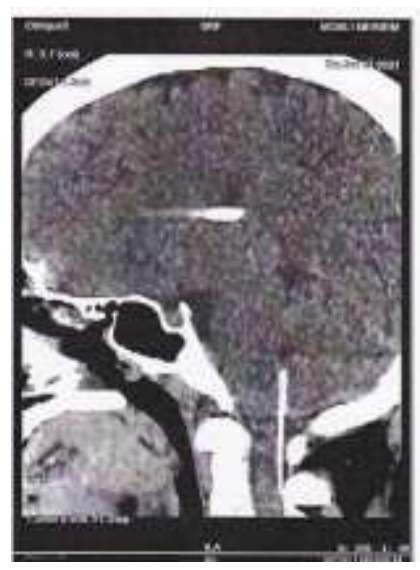

Figure 2: Profile image showing the end of the valve facing V4

\begin{tabular}{ll}
\hline $\begin{array}{l}\text { Standard radios with a cerebral and lumbosacral CT scan were carried } \\
\text { out in the patient objectifying the migration of the end of the proximal }\end{array}$ & $\begin{array}{l}\text { valve at the height of D4 UNTIL 4th Ventricle and the distal end in } \\
\text { intraspinal (explaining her sciatica) }\end{array}$
\end{tabular}

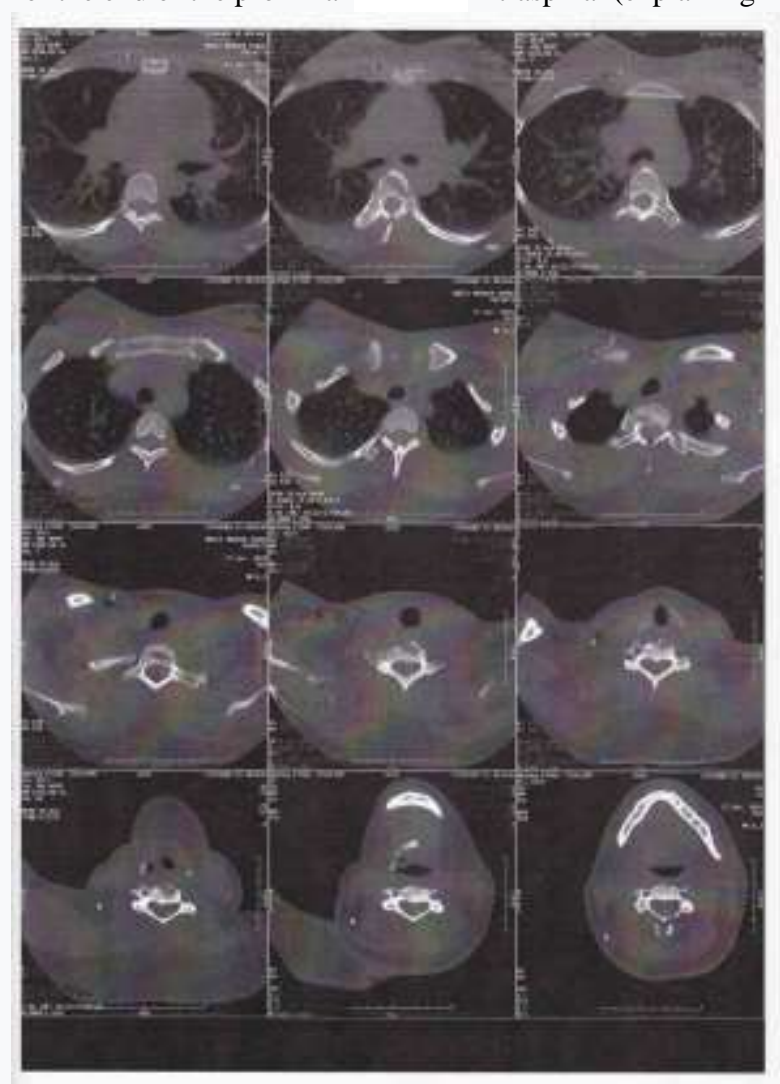

Figure 3: Migration of an extended shunt probe opposite D4 to V4 at the top

As any surgical indication to remove the valve is contraindicated, the decision to place a second ventriculio-peritoneal valve was discussed in our patient with resolution of these clinical signs.

\section{DISCUSSION}

BENIGNE intracranial hypertension, isolated without identifiable cause, very common in young obese women. The picture is dominated by headaches and visual disturbances. To discuss benign $\mathrm{CHI}$, brain magnetic resonance imaging (MRI) should be normal, cerebrospinal fluid pressure (CSF) high, and SCL analysis should be normal. [3] 
The goal of treatment for this condition is to reduce intracranial pressure (ICP) and prevent progression to blindness with headache relief.

The treatment regimen is based on medical treatment with Acetazolamide; repeated lumbar punctures (PL). Surgical treatment is recommended in cases where visual function is threatened [4]

Two types of CSF shunt can be offered: lumbopperitoneal (LPS) or ventriculoperitoneal (VPS) shunt.

Generally, the surgical technique performed is one of the factors incriminated in the occurrence of complications (aseptic conditions not respected, incorrect placement of the shunt, migration, early obstruction by a CSF too loaded with particles, deficient skin closure, etc.).

Intracranial migration from the proximal end of the catheter into the cerebral ventricle is a rare mechanical complication described by leads [5] to explain this migration, it may be due to a significant increase in intraabdominal pressure (our patient was pregnant) to propel the intracranial system and the poor fixation of the bypass system (a revision of the valve undergone by our patient).

\section{CONCLUSION}

In front of the reappearance of the clinical signs evoking a dysfunction of the valve, one carries out radiographs of all the valve device in search of a disconnection or migration namely X-rays of the cranium, X-rays thoracoabdominal and à new scanner.
And in order to limit the mechanical and infectious complications of the valves, stringent aseptic conditions must be met and the valve device must be firmly and securely attached to the underlying anatomical structures.

\section{REFERENCES}

1. F.Caire, E.M. Gueye, D. Fischer-Lokou, A.Durand ,M-P. Martel Boncœur,P-A. Faure, J-J.Moreau. hydrocéphalie de l'enfant et de l'adulte.EMC(Elsevier Masson SAS,Paris),Neurologie,17-160-C-40,2009.

2. SAINTE-ROSE C., PIATT J.H., RENIER D., ET AL. Mechanical complications in shunts. Pediatr. Neurosurg. 1991, 92 (17) : 2-9.

3. Bidot S, Biousse V, Bousser MG. Hypertension intracrânienne idiopathique.EMC -Neurologie.2006 JANV;11 (1):1-10. Google Scholar

4. Lee AG, WALL M. Idiopathic intracranial hypertension (pseudotumor cerebri): prognosis and treatment. 2013 -Springer. Google Scholar

5. SHIMIZU S., MOCHIZUKI T., NAKAYAMA K., ET AL. Visuel field defect due to a shunt valve migration into the cranium. Acta Neurochir. (2002), 144: 1055-1056. LE MELANOME ACHROMIQUE INTRA ORBITAIRE 49

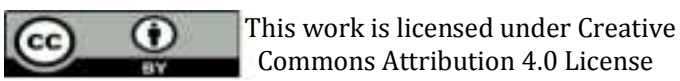

To Submit Your Article Click Here: Submit Manuscript

DOI:10.31579/2692-9392/0100
Ready to submit your research? Choose Auctores and benefit from:

fast, convenient online submission

* rigorous peer review by experienced research in your field

* rapid publication on acceptance

* authors retain copyrights

* unique DOI for all articles

* immediate, unrestricted online access

At Auctores, research is always in progress.

Learn more www.auctoresonline.org/journals/archives-of-medical-casereports-and-case-study 